\title{
THE USE OF ORTHOPAEDIC APPLIANCES IN THE TREATMENT OF ANTERIOR POLIOMYELITIS
}

\author{
By NoRMan CAPENER, F.R.C.S.
}

Orthopaedic Surgeon, Princess Elizabeth Orthopaedic Hospital, Exeter; Mount Gold Orthopaedic Hospital, Plymouth; Dame Hannah Rogers Orthopaedic Hospital, Ivybridge

Before the era of aseptic surgery, the use of external apparatus applied to the human form was a dominant feature of orthopaedic practice. In the treatment of anterior poliomyelitis it is still important, even though the advance of operative orthopaedics has done so much to remove from patients such stigmata of crippledom. In this disease the need for the support of unstable limbs and the control of deformity has been recognized, but there has also often been a tendency to impose rigid immobilization as well, with the object of preventing the stretching of paralysed muscles. Modern workers have returned to some of the earlier ideas of mobility and the viewpoint is well expressed by Seddon (1948) who recently stated :- ' there is no longer any doubt that denervated muscles do not degenerate as does a divided nerve. Such muscles merely atrophy and, therefore, to put them through the full range of movement is no more harmful than to stretch a normal muscle, though maintenance of a muscle in' an overstretched position is clearly harmful whether the muscle is denervated or not.'

\section{Purposes of Appliances}

Orthopaedic appliances are used for the following purposes :-

(a) Support for a limb to oppose the influence of gravity.

(b) Immobilization or limitation of movement of joints.

(c) Correction of deformity.

(d) Mobilization of joints.

(e) Assistance of or substitution for defective muscles.

Appliances used for these purposes are generally called 'splints,' which is somewhat unfortunate for it happens that the word splint has come to mean a rigidly immobilizing device. It is of interest to note that in medieval times the movable sections of suits of armour-for example, at the elbow or knee-were called 'splints,' and it is from this that the modern word is derived. Too many of the appliances at present used in the treatment of anterior poliomyelitis are based on splints used in the treatment of fractures in which the need for support and immobilization plays a bigger part. Although much ingenuity has been exercised by many generations of surgeons upon the design of splints including those providing mobility, the subject is one meriting still further interest in view of the advances in engineering science and of the improved materials now available.

\section{Physiological Control}

The ultimate basis of the development of modern orthopaedics is the principle of physiological rest. Too much emphasis has been placed upon the element of ' rest " and too little on the word 'physiological.' It might be better to use the term 'physiological control,' which would embrace the concepts of both rest and activity.

\section{Definition}

' Physiological control means the process giving control of part, or the whole of the body in the posture most favourable for the biological processes of growth and repair ; it provides rest to the extent required in the particular disease or injury being treated, while safeguarding functional restoration. It is not necessarily absolute or uninterrupted rest though for some period it may be. Its purposes are to promote healing, by avoiding the aggravation of pathological processes and by making available the whole metabolic resources of the patient. It is planned so as to prevent the deforming influences of extrinsic forces such as gravity, and of intrinsic forces such as unbalanced muscular activity, muscle spasm, atrophy, etc. Muscular activity is controlled or assisted according to the type of lesion. All treatment must be planned within the most favourable general background for physical and psychological health' (Capener, 1946). Such a statement applies to any pathological process.

During the acute stage of poliomyelitis while there are general constitutional disturbances and while muscle tenderness, pain and spasm remain prominent features the element of rest is obviously of greater importance. At this time the affected limbs must be supported in physiological positions, which are, as it were, the axes from which the 
Table Showing the Optimal Positions for Physiological Control

\begin{tabular}{|c|c|c|}
\hline Joint & Position & Remarks \\
\hline Shoulder & $\begin{array}{l}\text { Abduction } 45^{\circ} \text {, flexion } 30^{\circ} \text {, external rota- } \\
\text { tion } 15^{\circ}\end{array}$ & $\begin{array}{l}\text { Prevents stiffness in adduction, capsular } \\
\text { stretching and subluxation of the joint }\end{array}$ \\
\hline Elbow & Extended to about $100^{\circ}$ & Safeguards elbow flexor muscles sufficiently \\
\hline Forearm & Mid prone-supine & $\begin{array}{l}\text { Pronation can more easily be achieved by } \\
\text { gravity and is more useful than supination }\end{array}$ \\
\hline Wrist & Extension $30^{\circ}$ & $\begin{array}{l}\text { The angle is measured upon the dorsum of } \\
\text { the radius and of the third metacarpal }\end{array}$ \\
\hline Digits and thumb & $\begin{array}{l}\text { All joints flexed about } 25^{\circ} \text {. Thumb abducted } \\
\text { and opposed moderately }\end{array}$ & $\begin{array}{l}\text { The hand as a unit is held in the position of } \\
\text { semi-grasp, the thumb practically con- } \\
\text { tinuing the line of the antero-lateral border of } \\
\text { the radius, the phalanges of all digits in the } \\
\text { position of natural relaxation, e.g. that } \\
\text { assumed when the normal hand is loose at } \\
\text { the side of the body. The vicious position } \\
\text { of metacarpo-phalangeal extension is avoided }\end{array}$ \\
\hline Spine & Normal curves maintained & $\begin{array}{l}\text { Flexion as well as lordosis of the lumbar spine } \\
\text { to be avoided }\end{array}$ \\
\hline Hip & Abduction $15^{\circ}$. No rotation. Flexion $20^{\circ}$ & \\
\hline Knee & Flexion $15^{\circ}$ & $\begin{array}{l}\text { The quadriceps is not stretched. Avoids } \\
\text { posterior capsular stretching and resultant } \\
\text { hyper-extension instability. }\end{array}$ \\
\hline Ankle & Right angle & $\begin{array}{l}\text { A few degrees below rather than above } \\
\text { preferable }\end{array}$ \\
\hline Tarsal joints & Neutral as to inversion or eversion & \\
\hline Toes & $\begin{array}{l}\text { Maintain flexion of M.T.P. joints and extension } \\
\text { of I.P. joints }\end{array}$ & $\begin{array}{l}\text { Aids the preservation of intrinsic muscular } \\
\text { activity }\end{array}$ \\
\hline
\end{tabular}

further treatment may be graduated and to which the limbs are returned.

\section{Physiological Positions}

For every normal joint there is a position which is optimal for the function of the limb-a position in which its controlling musculature is able to exert its power to best advantage. These positions are not fixed but vary within a moderate range generally near the middle of the normal range of movement of the joint. Such intermediate positions, slightly modified in favour of the muscles chiefly concerned with opposition to gravity in the erect posture, are generally applicable to any type of poliomyelitis involvement, both for relative immobilization in the acute stage and for the resting position when exercise is allowed.

In the acute stages of poliomyelitis these positions are retained in recumbency unless paralysis is confined to the distal part of the upper extremity. Here it must be recognized that the first and most important splint is the bed itself to which very little in the way of special apparatus need be added to hold the positions outlined. This stage of treatment is largely a matter of general nursing care and will not be discussed further in this article.

\section{Reciprocal Innervation and Peripheral Stimulation by Movement}

Disturbances of reciprocal innervation and the central inhibition of muscular activity have become increasingly recognized as difficulties in the reeducation of poliomyelitics. The problem is to get stimuli from the consciousness of the patient to individual recovering muscles, for it must be $\sigma$ recognized that the consciousness itself has no $N$ concern with the action of individual muscles but $\mathcal{\omega}_{\mathrm{W}}$ is concerned with the initiation of intention and $\sigma$ the direction of this to purposeful movement of limbs or part of the body. The execution of $\underset{D}{\mathbb{C}}$ movement involves a co-ordinated pattern of $\stackrel{\oplus}{\rightarrow}$ muscular activity of which the control is influenced by the flow of proprioceptive impulses from muscles, tendons and ligaments, as well as by impulses of superficial sensory origin. Reflex 


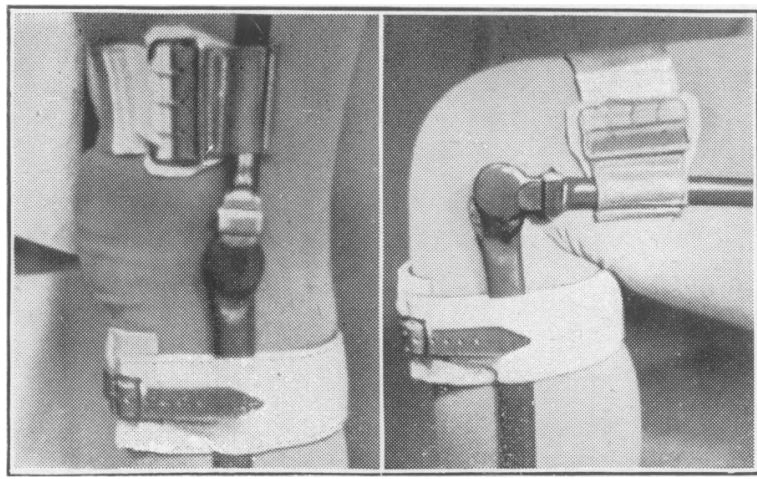

FIG. I.-The jointed knee caliper.

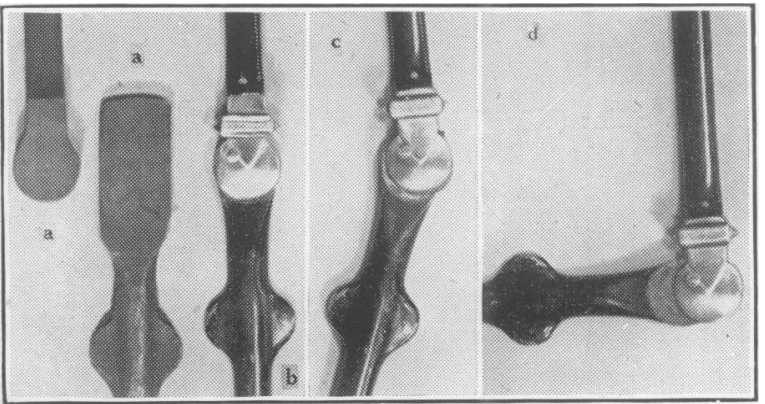

Fig. 2.- Jointed caliper locking device. (a) Rough hand forging; (b) the finished joint locked; (c) semi-flexed, showing the locking spike disappearing within the circle; (d) in further flexion, complete disappearance of spike. Note eccentric movement which permits this and provides easing of pressure on the calf band in flexion.

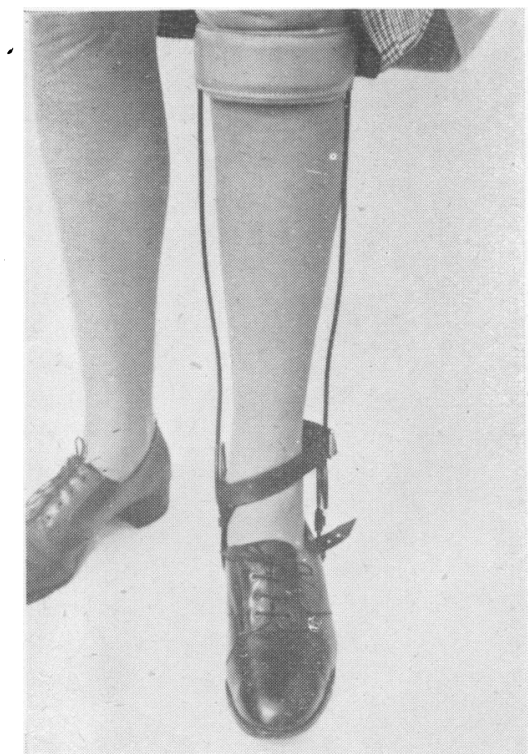

Fig. 4.-Exeter toe-raising coil splint for drop foot.

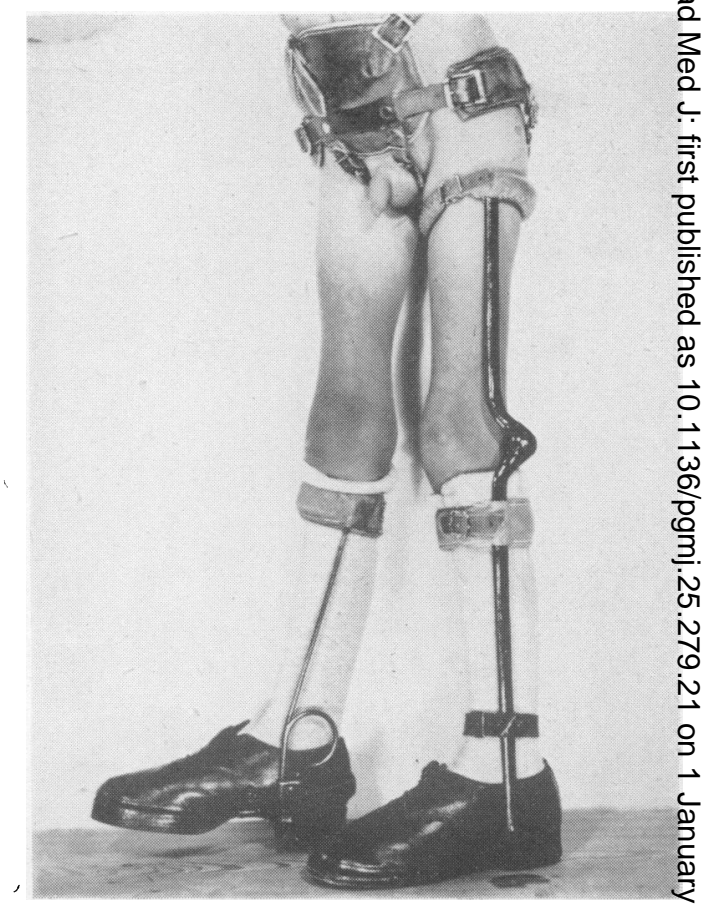

FIr. 3.-Special jointed caliper with postere $\overrightarrow{0}$ hinge, giving considerable stability in exter - .0 sion. No locking device is required. Illkîtration also shows Exeter toe-raising coul. 


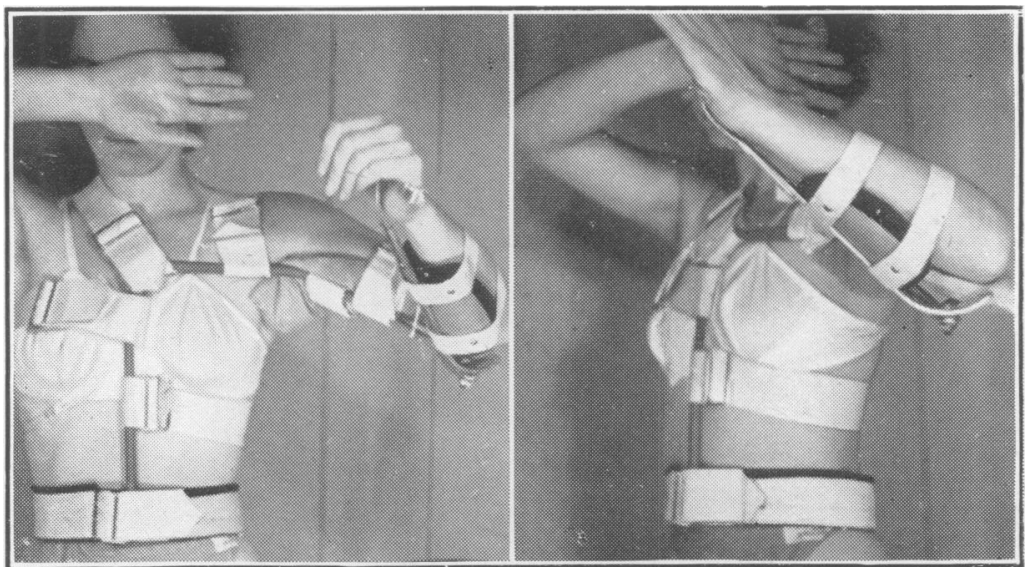

Fig. 6.-Adjustable Littler-Jones abduction sṕlint (Wingfield-Morris type).
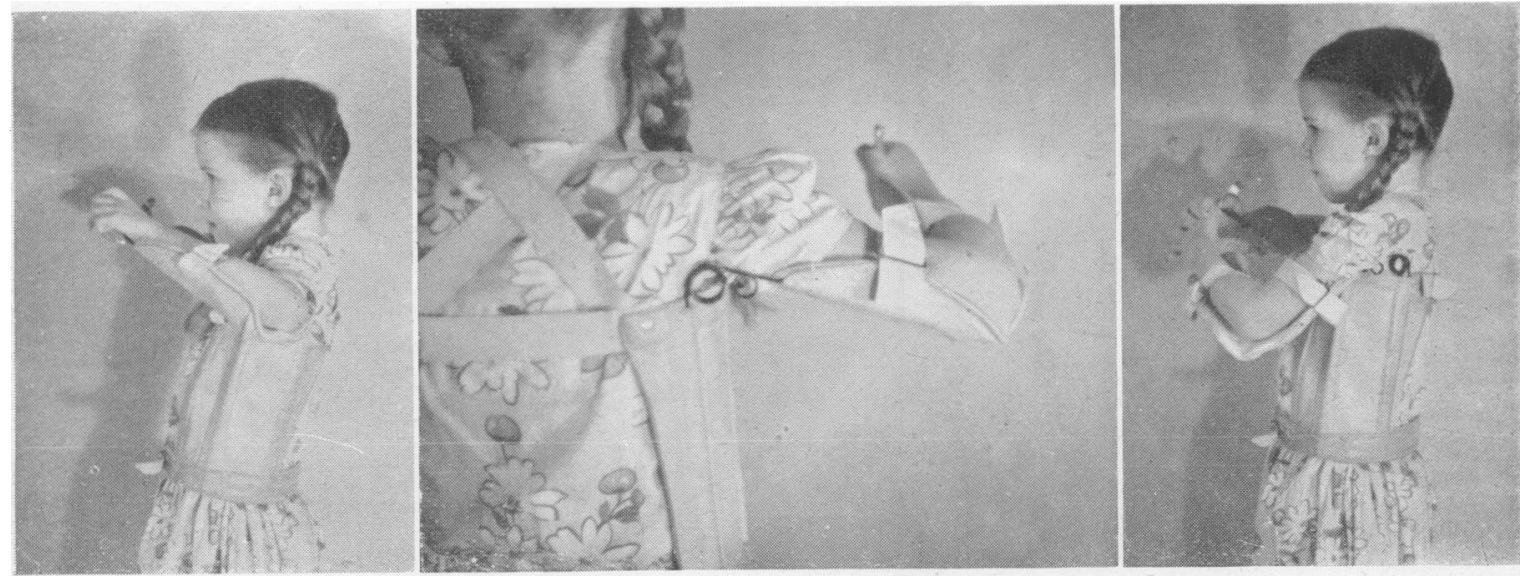

FIG. 7.-A ' lively' shoulder abduction splint.

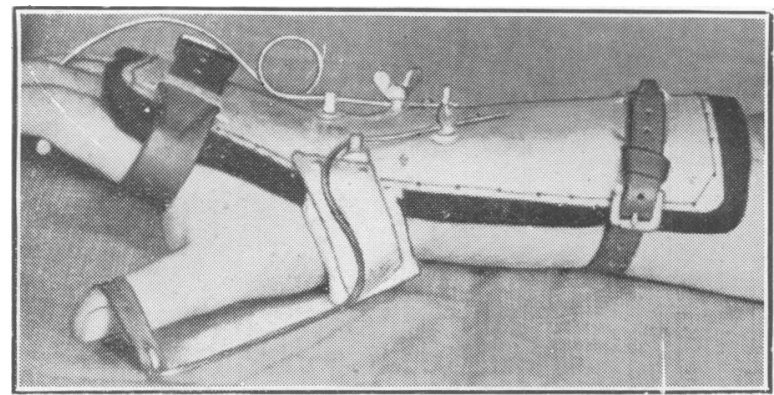

FIs. 8.-Brian Thomas extensor appliance (Exeter model). 


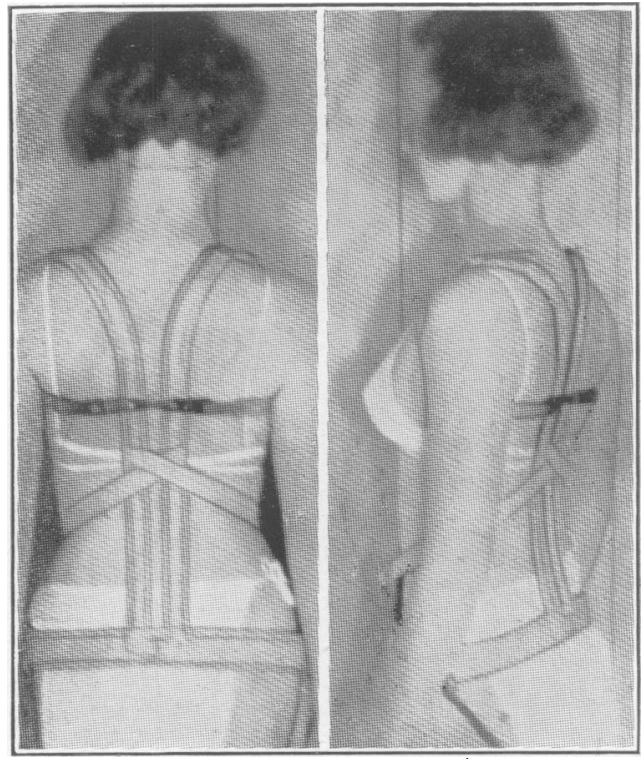

FIG. 14.-The Taylor spinal brace.
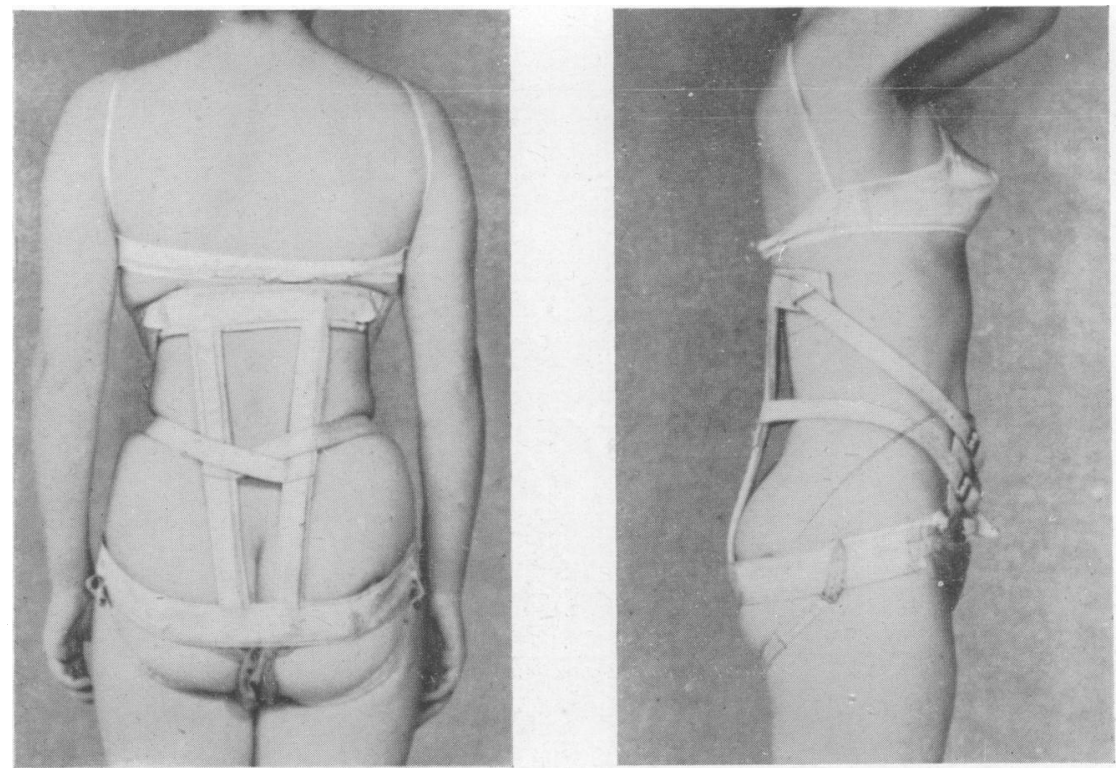

Fig. 15.-Goldthwaite spinal brace. 

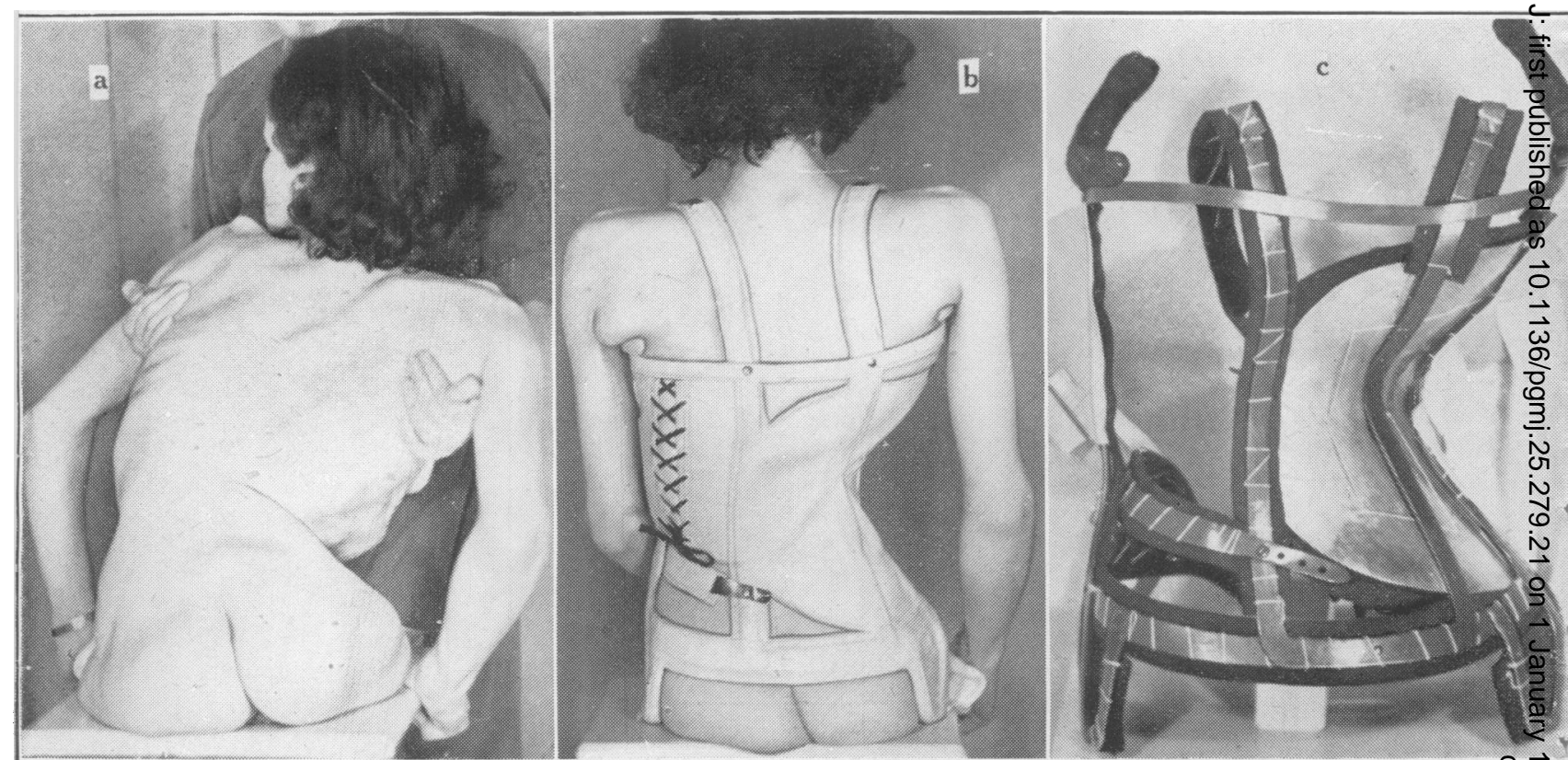

FIG. 16.-(a) Paralytıc scoliosis showing inability to sit without support; (b) the same patient with true spinal support taken from seat ; (c) the same appliance in the course of manufacture.

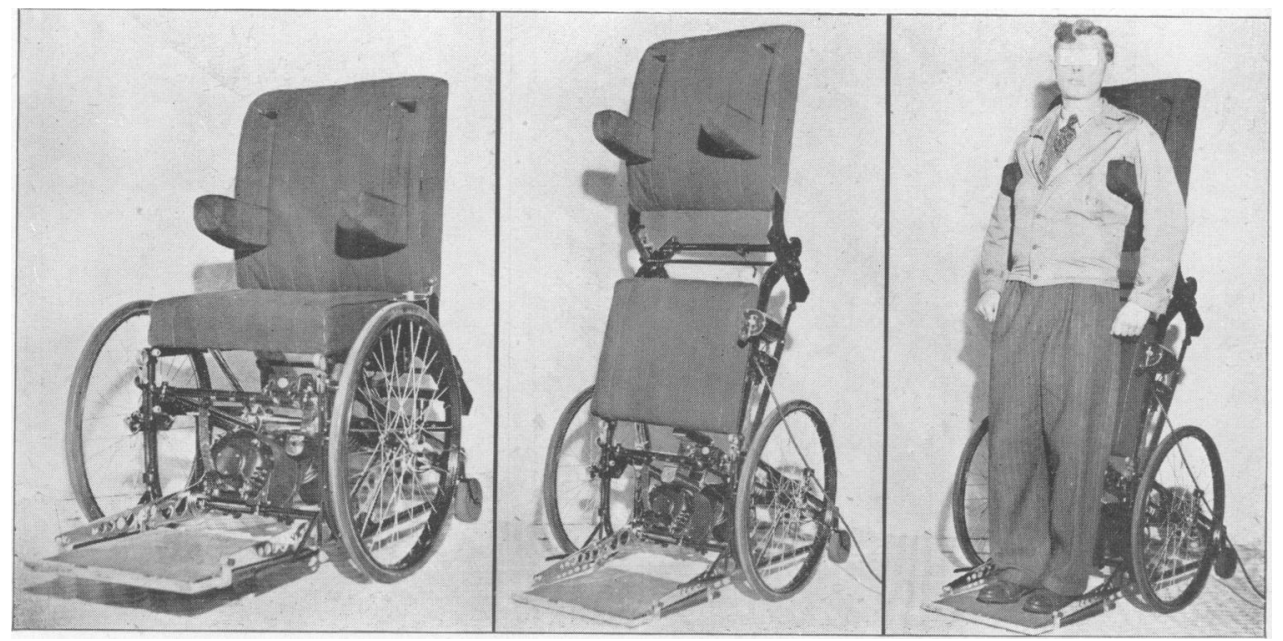

FIG. 17.- Invalid chair designed by J. E. Gull. 
stimulation from the periphery of the lower motor neurone is affected by the controlling influence of the basal ganglia. While the maintenance of proprioceptive stimulation need not necessarily be invoked as a direct means of affecting central inhibition, nevertheless the restoration of this peripheral flow of impulses at an early date by establishing reflex activity in the spinal reflex system, should do much to maintain it in a fit state to respond to central stimulation as soon as this is possible. Such physiological stimulation of muscular activity from the peripheral sensory impulses is the basis of much of the physical therapeutic treatment of poliomyelitis and peripheral nerve injuries and could be used very. much more often mechanically if the design of orthopaedic appliances for poliomyelitis were based particularly upon the idea of mobilization or ' liveliness'; a point which will be emphasized in the following discussion of individual splints.

\section{Appliances for the Lower Extremity}

The basic appliances for the lower extremity from which others have been evolved are the long and short caliper.

\section{The Thomas Caliper}

This familiar appliance was designed primarily for the support of body weight and for immobilization. In the common form, manufacture is from $\frac{8}{8}$ in. mild steel rod reduced to $\frac{1}{4}$ in. diameter where it fits into the heel of a shoe and with a leathercovered and padded oval ring set obliquely at its top at an angle of $30^{\circ}$. For short term use a design has been invented by Mr. J. Charnley (1947) which is available for mass production. For poliomyelitis the half ring cuff-topped caliper not bearing weight under the tuberosity of the ischium is preferable to either of these on account of its ease of adjustment. Such rigid calipers are completed by a supporting strap behind the knee and by a retaining pad in front of this joint, both made of leather. The advantages of such appliances are their simplicity and ease of manufacture and the readiness with which patients can at a relatively early date become ambulatory. Even where such appliances are made to take weight from the tuberosity of the ischium, they do not provide any useful support for the gluteal muscles, the control of which at the moment is essentially an unsolved problem. For long term needs the caliper should be provided with locking joints at the knee. A very useful type is one with an eccentric pivot placed behind the long axis of the side irons of the appliance which at the joint are expanded into a circular form. This circular form gives greater stability by providing a bigger surface for friction and permits the disappearance in flexion within the circle of the locking spike which, in the more usual designs, causes undue wear upon the patient's clothes. Another advantage of this eccentric joint is that in flexion the rigid calf band of the appliance tends to move away from the calf and relaxes pressure upon this region.

In the manufacture of this appliance ' double sheer' steel may be employed. This is a hard steel and, therefore, maximal reduction in weight may be given with the relative absence of bend or wear in the finished product. Some appliance makers and surgeons (of whom the writer is one) prefer the use of mild steel which is hand forged and is case hardened at the joints. This permits easier adjustment of shape in the cold and if the uprights are fashioned in proper cross section (broader from before backwards) are of comparable strength and lightness.

\section{The Short Caliper}

In cases in which the thigh muscles have good power the short caliper may be employed to control the foot and ankle joints and to support the muscles involved. In its simplest form this appliance comprises a flat half-ringed band of mild steel covered with leather and completed with a strap in front placed at the level of the tuberosity of the tibia and the head of the fibula, the uprights consisting of mild steel rod or flat metal attached to the sides of the metal half ring above and inserted into tubes in the heel as described for the long caliper. From the side of the boot may be attached T-straps, the upper limbs of which encircle the ankle and the iron upright on the opposite side, to control either valgus or varus respectively. A valgus T-strap may be replaced by the provision of a strap inside the shoe passing obliquely from the outer side of the foot underneath the long arch and attached to the outside iron at a higher level giving special support to the inner longitudinal arch and the tibialis anterior muscle. In cases in which there is valgus weakness the addition of a Thomas heel to the shoe is usual. This comprises a forward extension of the inner border of the heel of approximately $I$ in. in an adult, with the insertion of a wedge of leather under the inner side of the heel of $\frac{3}{16}$ in. to $\frac{1}{4}$ in. thickness. In such cases it is not advisable to wedge the inner side of the sole, for good walking depends upon the firm pressure of the first metatarsal head upon the ground, a function of the peroneus longus.

In all these-devices the heel tube to which the uprights are inserted may comprise a simple $\frac{1}{4}$ in. metal tube fixed by a transfixion nail through the leather work and containing graphite lubricant. It is better, however, that it should be welded to 
a metal plate fixed under the welt. It should always be placed so that the tube lies under the centre of the ankle joint and transversely to the line of the limb in walking. Variations to the shape of the heel plate may be provided, such as a back stop of metal which extends upwards from behind the tube and which, by abutting upon the back of the upright iron, can be made to prevent drop foot. The tube may be oblong in cross section to receive a flattened lower end of the upright iron thus rigidly limiting both upward and downward movement of the foot.

To a short caliper may be fitted a toe raising spring which in its simplest form is attached by means of a V-strap higher up on the vertical irons and its lower end fixed to a hook stitched into the leather work of the shoe in front of the lacing. In the workshops of the Devonian Orthopaedic Association at Exeter has been developed a very light spring device which converts the short caliper itself into a spring which controls the foot. The metal half ring at the top lies in front of the leg for easier adjustment. The spring may be arranged so as to maintain the foot in the neutral position, to provide dorsiflexion, or by reversing it (i.e. by placing it back to front on the shoe) to provide some assistance to the calf muscles. The spring material is of $\frac{1}{8}$ in. wire made from a special alloy which can be worked in the cold, and is not highly brittle.

\section{Appliances for the Upper Extremity}

The appliance which corresponds to the Thomas leg caliper in its universality for the upper extremity is the Littler-Jones abduction splint. This, in the modified version developed by the Wingfield-Morris orthopaedic workshops at $\mathrm{Ox}$ ford, is manufactured from $\frac{1}{4}$ in. mild steel rod in one continuous piece forming a half circle round the body at the waist line and continued upwards vertically from the mid line both back and front to the shoulder level, where it curves outwards to the shoulder joint level and then downwards and forwards in the line of the limb. The posterior and anterior portions of the wire are continuous at the elbow, beneath which they dip, and here are fashioned to receive an adjustable forearm splint comprising a small malleable gutter with a rod extension into the palm which receives a transverse hand grip. The forearm splint has a curved backward extension which provides the fitment at the elbow and which is so arranged as to permit variable degrees of external rotation of the shoulder. Correctly made this appliance is only applicable to one side of the body because it is shaped to provide forward flexion of the shoulder at an angle of $30^{\circ}$ and abduction of the shoulder not less than $45^{\circ}$. In the design of this appliance there is no reason why the principle of spring action should not be adopted for assistance to the deltoid muscle, and an illustration of such application is given (Fig. 7).

\section{The Hand and Forearm}

In paralytic lesions of the lower part of the upper extremity the need for the maintenance of mobility is particularly great. Much can be done by these means to maintain the circulatory condition of the limb, to prevent the contractures due to muscular atrophy and fibrosis and the stiffness of joints which may supervene. There is a tendency in the design of apparatus to remove material from the palmar surface of the limb, thus leaving this freer for use. This tendency does aid in the sensory stimulation of the spinal reflexes as I have already outlined. Examples of such substitution devices and mobilizing splints are seen in the appliance sponsored by the Medical Research Council Peripheral Nerve Injury Committee in the first World War (M.R.C. 1920). Physiologically this splint was not entirely satisfactory, for the application of extension was to the terminal phalanges of the fingers and thumb instead of to the proximal phalanges where extension force was deficient. It also had an undesirable feature in being provided by a cock-up splint for the wrist which covered the useful sensory area of the palmar skin. During the recent war Brian Thomas (1944) replaced the digital extensors by using a dorsal spring wire with a cross bar under the proximal phalanges; his dorsal plate left the palmar surface of the hand much freer. Bunnel (1946) of San Francisco and Bateman (1946) of Toronto have developed similar devices. At Exeter we have adapted the idea of the Brian Thomas splint, first of all modifying it by coiling the spring to give an easier action, thus diminishing the tendency to produce hyperextension of the metacarpo-phalangeal joints, and later have evolved a series of appliances based upon a simple cock-up splint for the wrist having structural details somewhat suggesting the Thomas caliper splint for the leg. In its simplest form this basic cock-up splint is made from a piece of mild steel $\frac{1}{8}$ in. rod with an ob ique section shaped to fit into the palm and lying anterior to the necks of the metacarpal bones. The rest of the splint is applied to the sides and dorsum of the wrist and forearm with one or two leather straps which encircle the limb. By using thinner spring wire instead of mild steel a coil can be placed in it at the level of the wrist so as to act as a lively dorsiflexor. On the principle of the basic cock-up splint can be erected a variety of attachments for specific purposes, such as springs for the mobilizing of stiff finger joints in flexion or for extension of the 


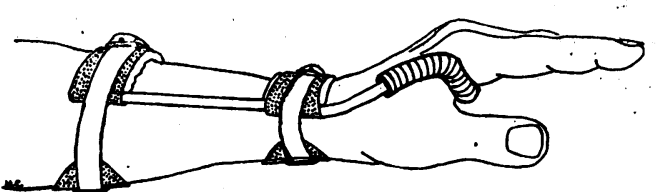

FIG. 9.-The 'basic' cock-up splint (giving maximum possibilities for palmar cutaneous sensibility).

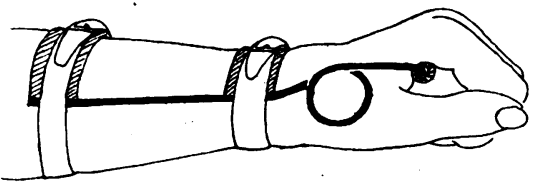

Fig. 10.-The ' lively' wrist extensor appliance.

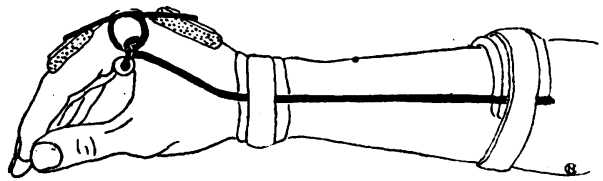

Fig. I1.-A combined wrist cock-up appliance with splint for intrinsic muscles.

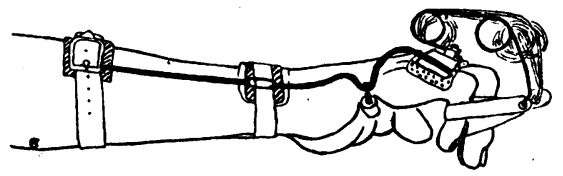

FIG. 12.-A wrist cock-up splint with mobile extensor mechanism for fingers in case of intrinsic paralysis with contracture.
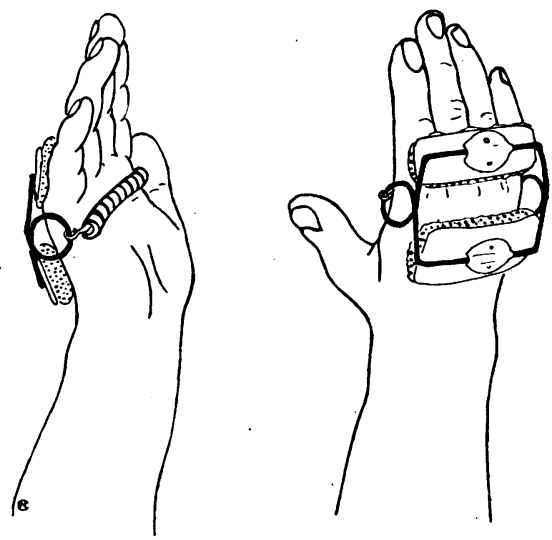

FIG. 13.-The simple spring appliance for intrinsic paralysis. metacarpo-phalangeal joints or of the interphalangeal joints. In the latter case the basic appliance is modified to provide a dorsal bar across the first phalanges so as effectively to prevent hyperextension of these joints, which is -so readily brought about by apparatus otherwise used for extension of the interphalangeal joints.

\section{Appliances for Intrinsic Paralysis}

It seems clear that the major purpose of the interosseous and lumbrical muscles of the hand is to flex the metacarpo-phalangeal joints. Various appliances have been devised to replace these muscles when paralysed; one such was invented during the recent war by the late Bremner Highet in the form of a rigid clip comprising a band across the palm and two dorsal bands passing across the metacarpals and proximal phalanges respectively. By maintaining the flexed position of the metacarpo-phalangeal joints this device enabled the common extensor muscles to produce more effective extension of the interphalangeal joints. A less rigid appliance was devised by Hendry of Birmingham who united these cross bars by added spiral springs to give the same effect in a more lively manner. At Exeter (Capener, 1946) a further improvement was devised by converting the whole appliance into one flexible spring using a continuous wire linking up all three components and having medial and lateral coils. In principle this splint will be seen to resemble closely the spring appliance for raising the paralysed foot.

\section{Appliances for the Spine}

The control of the spine and the prevention of deformity brings the most serious problems for solution by the orthopaedic appliance maker. The difficulties are produced not only by the complexities of the intrinsic musculature of the spine itself but, in addition, because it is so seriously affected by the paralytic phenomena of the limbs and the disturbances of body mechanics which they produce, and on account of the profound effect upon the spine of paralysis of important extrinsic muscles such as the psoas and gluteal muscles, which are so important in controlling the position of the pelvis upon the lower extremities.

The commonly used spinal supports, because they limit flexion of the spine, are of limited use in anterior poliomyelitis, for not often is there serious loss in the extensor elements of the sacro-spinalis group. Disturbances of the anterior and lateral abdominal muscles are, however, commoner and for these spinal supports provide little help. Abdominal belts with elastic insertions have a place. Where however a more rigid support is needed, the type of appliance devised by Gold- 
thwaite is recommended. This is more in use in the United States than it is in Great Britain and, in its original form, is worthy of more consideration. It is designed on physiological principles taking three point pressure, over the lower dorsal region at the back above, over the lower abdomen in front and over both buttocks at the back. It leaves the upper abdomen entirely free for respiration and it can be fitted with added shoulder straps to encourage the maintenance of shoulder girdle posture. The metal work is made from flat spring steel strips, leather covered (Capener, 1947).

The manufacture of a well-fitted leather girdle of tough hide shaped to the contours of the pelvis, and the attachment of this to long caliper appliances by hinges at the hip joint levels does provide a means of giving some stability to the basis of the spine in severe hip muscle paralysis, but it cannot fully compensate for the loss of these muscles nor can it control effectively the distressing ' gluteal gait' seen in some cases with severe associated paralysis of the lateral abdominal muscles and the abductors of the hip. In some clinics in cases with such severe paralysis of the spine and hip muscles long leg appliances are fitted to extensions which articulate with steel spinal supports; though theoretically these give some further assistance, nevertheless the added weight of the appliance often negatives the benefit which might otherwise be expected. For a patient with the concertina-like collapse of severe paralytic scoliosis a great deal of help can be provided by a skilfully made spinal support built upon a plaster cast prepared under moderate traction applied to the head. Such supports require the highest craftsmanship. The metal work at points of special stress is usually of tempered spring steel and shaped under heat treatment; where malleability is required mild steel strips are employed. Where rigid support is required over considerable surfaces light aluminium or dural sheets are hammered into shape. Arm crutches and other parts coming into direct contact with skin are covered over a thin layer of felt, with the finest kid or basil leather.

The patient illustrated with such an appliance, although completely paralysed in both legs and restricted to a wheel chair existence, was able to manage a normal household including cooking, which previously had been impossible (Fig. I6).

\section{Ambulation by the Seriously Paralysed Patient}

Much can be done by operative treatment to remove the need for orthopaedic appliances particularly in the lower extremity. Without such operative treatment it often is remarkable how much an individual with determination can do with appliances (and sometimes without them) once he or she is in the upright position with crutches. The difficulty is to get into that position without help. To solve this problem an engineer, Mr. John Gull (1948), has devised a mechanical chair with an electric motor which will effectively raise or lower the individual from or to a sitting position without external aid.

In all the research, that has been done upon the splints described, I am greatly indebted to $\mathrm{Mr}$. F. W. Suter-technical director of the Devonian Orthopaedic Association Workshops; The Princess Elizabeth Orthopaedic Hospital, Exeterfor his invaluable assistance and superb craftsmanship.

For permission to reproduce Figs. 1, 2, 6, 8, 1网 and 16 , the author is indebted to the 'Editor of the British Medical fournal. Fig. 15 is included by courtesy of the publishers of Butterworth's British Surgical Practice, and Fig. I7, of the Editors of the 'Proceedings of the Royal Society of Medicine.'

\section{BIBLIOGRAPHY}

BATEMAN, J. E. (1946), fourn. Bone \&5 foint Surg., 28, 169. BUNNELL, S. (1946), fourn. Bone \&5 foint Surg., 28, 732. CAPENER, N. (1946), B.M.f., ii, 761.

CAPENER, N. (1947), 'British Surgical Practice,' Vol II, Butterworth, London.

CHARNLEY, J. (1947), Lancet, ii, 464.

GULL, J. E. (1948), Proc. R.S.M., 51, 381 .

Med. Res. Cncl. Sp. Rep. Ser. No. 54 (1920), H.M.S.O., London, reprinted 1942.

SEDDON, H. J. (1948), 'Discussion on Anterior Poliomyelitis,' Royal Society of Medicine.

THOMAS, F. BRIAN, (1944), fourn. Bone E゚ foint Surg.. 26. 602

Evidence to support the theory that severe physical activity during the preparalytic stage of infantile paralysis predisposes to severe paralysis is adduced by Hargreaves (Brit. Med. four. 1948, 2, 1022). In the 30 cases occurring in Cornwall during the 1947 epidemic there were six deaths. Of these six, five had undertaken severe physical strain during the days immediately preceding the paralysis, whilst the sixth had done moderate work. This would appear to confirm Russell's statement (Brit. Med. Four. 1947, 2, 1023) that complete physical rest in bed during the whole of the preparalytic stage seems to protect the patient from severe paralysis. 